\title{
Study of Additional Chromosomal Abnormalities in Young Adult Egyptian Chronic Myeloid Leukemia Patients
}

\author{
Prof. Mohamed Osman Azzazi, MD*, Prof. Mohamed Mahmoud Moussa, \\ MD *, Dr. Mohamed Tarif Mohamed Hamza, MD **, Dr. Amro Mohamed \\ Sedky El-Ghammaz, MD *, Asmaa Mohammed Elsayed Eissa ,Msc* \\ * Hematology and BMT Department, Faculty of Medicine - Ain Shams \\ University, ** Clinical Pathology Department, Faculty of Medicine - Ain Shams \\ University.
}

\section{Background}

\section{Abstract}

Outcome in chronic myeloid leukemia (CML) have improved with tyrosine kinase inhibitor treatment (TKI). Additional chromosomal abnormalities (ACAs) are strongly associated with disease progression but their prognostic impact and influence on treatment response in young adults are yet to be defined. The aim of this study was to analyze the impact of ACAs in Egyptian young adult CML patients on response to treatment.

Materials and methods: The data from the Hematology Department and outpatient clinic of Ain Shams University was collected from young adult CML.

Results: At presentation, ACAS were found in 7 patients (8\%). During treatment, 4 patients of them had achieved molecular response. While during treatment, ACAS were found in 10 patients. 4 patients of them had achieved molecular response. Also during treatment, chromosome 17 abnormalities were found in 4 patients. Three patients of them didn't achieve molecular response and shifted to tasigna.

Conclusion: ACAS at diagnosis and during treatment has no impact on CML poor risk parameters which denotes that other factors are more significant .Time to molecular response didn't differ between ACAS +ve \&-ve patients at diagnosis

\section{Introduction}

$\boldsymbol{B C R}-\boldsymbol{A B L 1}$ is the primary driver in CML and is the sole chromosomal abnormality in $80-90 \%$ of cases in chronic phase (Wang et al., 2015). CML incidence rates in western countries vary from 0.6 to 2.0 cases per 100,000 inhabitants (Azzazi and Mattar, 2013). Recent studies have demonstrated the median age to be 45-55 years (Babu et al., 2015).

CML is a multiphase disease, which may be diagnosed in three distinct phases: chronic phase (CP), accelerated phase (AP) and blast phase known as blast crisis (BP). Most patients are diagnosed in CP (Crisan et al., 2015). 
As the disease progresses clonal evolution with additional chromosomal abnormalities (ACAs) occurs. The most common ACAs in CML include trisomy 8, an extracopy of Philadelphia chromosome (Ph), i(17)(q10), and trisomy 19. These are so called "major route" changes as described in literature. Other less common ACAs are "minor route" changes. ACAs are considered as an indicator of disease progression (Wang etal.,2015). The World Health Organization (WHO) classification suggests that those patients showing ACAs emerging during treatment should be considered in accelerated phase (AP). The European Leukemia Net recommendations suggest that the presence of ACAs at diagnosis may represent a "warning" feature, requiring careful monitoring of the patient (Luatti et al., 2012).

In this study we analysed the impact of ACAS on the outcome of the Egyptian young adult CML.

\section{Materials and Methods}

Newly diagnosed patients with CML who were registered in our hospital between 2007 and 2016 were enrolled in the study. Patients were followed up for a total duration of 9 years. Patients were included in the study after obtaining written informed consent. Spleen size, total count, basophil and eosinophil counts, platelet count, cytogenetic abnormalities, and reverse transcriptse-polymerase chain reaction (RT-PCR) for BCR-ABL were documented at baseline. Cytogenetic analysis was performed by karyotyping at baseline in all patients using the International System for Human Cytogenetic Nomenclature (ISCN, 2009).

All patients were started on imatinib $400 \mathrm{mg} /$ day po. Patients were followed up at regular intervals for response assessment. Hemograms were done every month to look for hematological response.PCR for $\mathrm{BCR}-\mathrm{ABL}$ on peripheral blood was performed every 3 months

26 patients were shifted to nilotinib or dasatinib. Patients were investigated for failure to achieve targeted guidelines after the appropriate time schedule based on ELN guidelines (Baccarani et a.,2013)

Patients with failure of response after 12 month performed second bone marrow karyotyping. Flouresent insitu hybridization for chromosome 17 abnormalities (ch17) using the following probe; Poseidon dual color single fusion p53 (17p13)/MPO (17q22) was performed in patients with ACAS in base line karyotyping and second one.

Statistical analysis was performed by SPSS version 21 IBM. Kaplan-Meir graph was used to depict overall survival. 


\section{Results}

During 2007-2016, 86 young adult CML patients were diagnosed and monitored in our department. The median age of patients was 32 years. By ultrasound splenomegaly was present in $76.4 \%$.

Conventional chromosomal study was done to 86 patients and revealed that 7 (8.1\%) of them had additional chromosomal anomalies (ACAS) and 79 (91.9\%) didn't (fig1) (table 1).

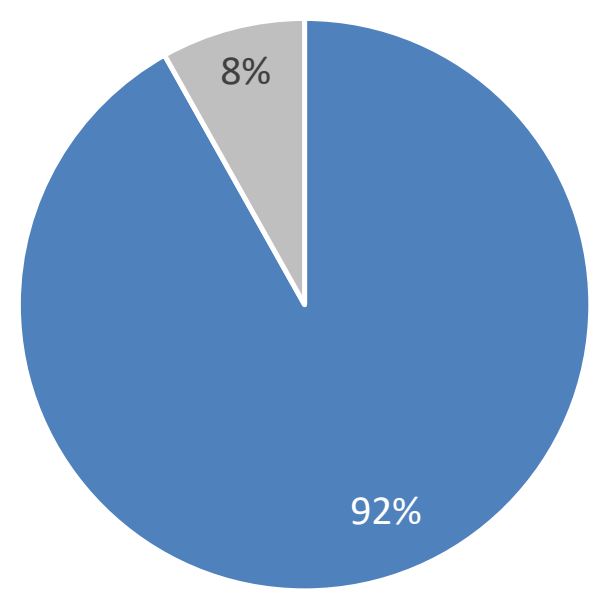

- ACAS Negative

- ACAS Positive

Figure (1) The destribution of additional chromsomal anomalies in the studied patints

Table (1): The ACAS before treatment

\begin{tabular}{||c|l|}
\hline No of patients & \multicolumn{1}{|c|}{ Type of abnormal chromosome } \\
\hline 1 & abnormal ph clone chromosome 3,9 14,22 \\
ph +ve and $\mathrm{t}(8 ; 22)$ \\
\hline 1 & $\begin{array}{l}\text { abnormal ph+ve with rearranged chromosome } \\
6 \& 10\end{array}$ \\
\hline 1 & Extra ph chromosome \\
\hline 2 & $47 x y$ ph+ve add (15q26)del (16q22) \\
\hline 1 & $\mathrm{t}(2 ; 7)$, del16 (q22)ph+ve \\
\hline
\end{tabular}


Table 2 illustrates the base line patient characteristics among those harboring ACAS and those who don't in first bone marrow karyotyping. There was insignificant difference between the two groups.

Table (2): Patients characteristics according to ACAs: in $1^{\text {st }}$ bone marrow karyotyping

\begin{tabular}{|c|c|c|c|}
\hline $\begin{array}{l}\text { Patients Characteristic } \\
(\mathrm{N}: 86),(\mathbf{1 0 0 \%})\end{array}$ & $\begin{array}{c}\text { ACAs +ve } \\
(\mathrm{N}: 7)\end{array}$ & $\begin{array}{c}\text { ACAs -ve } \\
(\mathrm{N}: 79)\end{array}$ & $P$ value \\
\hline Age (Mean, SD) & $31.7( \pm 6.9)$ & $33( \pm 7.8)$ & 0.673 \\
\hline Sex, male/female, $(\%)$ & $1 / 6(14.3 / 85.7)$ & $31 / 48(39.2 / 60.8)$ & 0.250 \\
\hline WBCs (Mean, SD) & $139( \pm 87)$ & $175( \pm 92)$ & 0.327 \\
\hline Hb level (Mean, SD), g/dL & $9.9( \pm 1.6)$ & $9.8( \pm 1.6)$ & 0.809 \\
\hline PLT count (Mean, SD & $473( \pm 216)$ & $401( \pm 352)$ & 0.601 \\
\hline Eosinophilsx (Mean, SD) & $2.6( \pm 2.3)$ & $3.2( \pm 2.6)$ & 0.520 \\
\hline Basophiles (Mean, SD) & $3.9( \pm 1.2)$ & $2.7( \pm 2.9)$ & 0.318 \\
\hline Peripheral blasts (Mean, SD) & $2.7( \pm 1.1)$ & $2.9( \pm 2.6)$ & 0.823 \\
\hline Hepatomegaly & $1 / 7$ & $20 / 78$ & 1 \\
\hline spleen (Mean, SD), cm & $22.5( \pm 8.5)$ & $18.3( \pm 4.98)$ & 0.285 \\
\hline Phase of CML & $\mathrm{N}(\%)$ & $\mathrm{N}(\%)$ & \\
\hline Chronic phase & $7(100 \%)$ & $77(97.5 \%)$ & 1 \\
\hline Accelerated phase & 0 & $2(2.5 \%)$ & \\
\hline \multicolumn{4}{|l|}{ Sokal score, } \\
\hline Low & $1(14.3 \%)$ & $39(49.4 \%)$ & 0.441 \\
\hline Intermediate & $6(85.7 \%)$ & $29(36.7 \%)$ & \\
\hline High & $0(0 \%)$ & $11(13.9 \%)$ & \\
\hline
\end{tabular}




\begin{tabular}{|c|c|c|c|}
\hline \multicolumn{3}{|c|}{ Hasford score } & \\
\hline Low & $3(42.9 \%)$ & $60(75.9 \%)$ & \multirow[t]{3}{*}{0.106} \\
\hline Intermediate & $4(57.1 \%)$ & $17(21.5 \%)$ & \\
\hline High & $0(0 \%)$ & $2(2.5 \%)$ & \\
\hline \multicolumn{3}{|c|}{ EUTOS score, } & \\
\hline Low & $6(85.7 \%)$ & $75(94.9 \%)$ & \multirow[t]{2}{*}{0.353} \\
\hline High & $1(14.3 \%)$ & $4(5.1 \%)$ & \\
\hline
\end{tabular}

Our patients started treatment with imatinib, complete hematologic response was achieved at 3 months in $73(84.9 \%), 7(8.1 \%)$ patients achieved complete hematologic response at 6 months, 3 cases died, another 3 (3.5\%) cases didn't achieve hematologic response (fig 2).

Regarding patients who shifted to nilotinib $8(32 \%)$ of them achieved major molecular response, $6(24 \%)$ achieved complete molecular response and regarding patients who continued on imatinib $28(35.9 \%)$ of them achieved major molecular response, $23(37.7 \%)$ achieved complete molecular response, there was no statististical significant correlation between type of treatment and response (table 3 ).

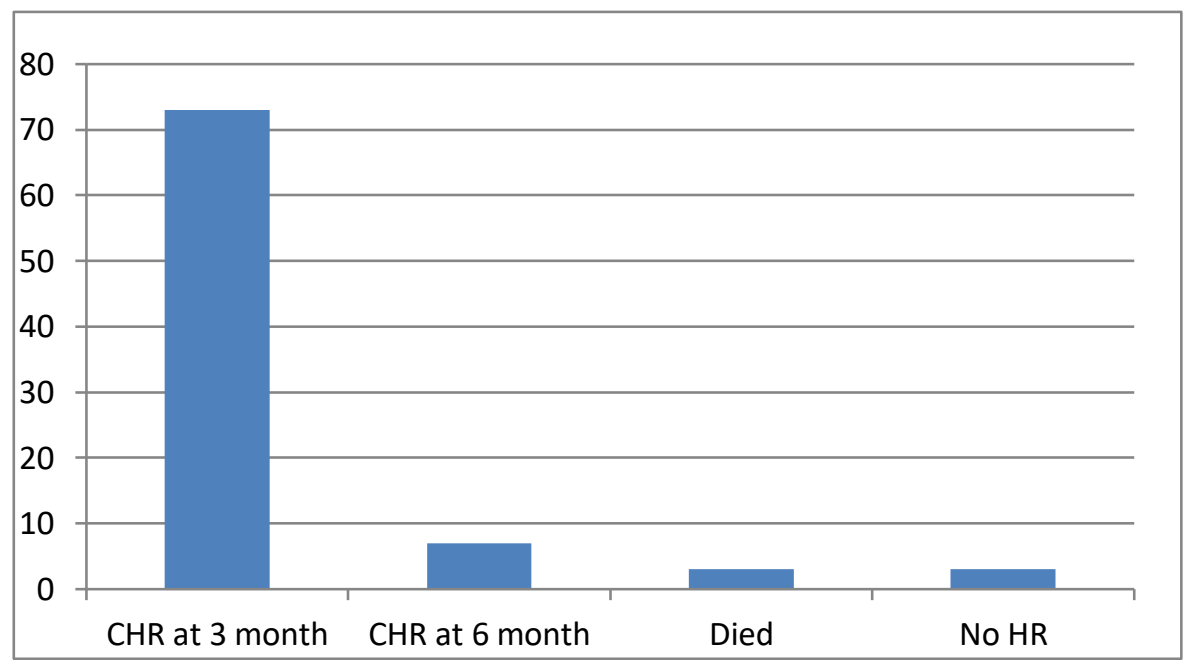

Figure (2): Hematological response 
Table (3): Molecular response

\begin{tabular}{|c|c|c|c|c|c|c|c|}
\hline & & & Complete & $\begin{array}{c}\text { Major } \\
\text { Molecular } \\
\text { Response }\end{array}$ & $\begin{array}{c}\text { Major } \\
\text { Molecular } \\
\text { Response } \\
\text { (MMR4.5) }\end{array}$ & $\begin{array}{c}\text { No } \\
\text { Molecular } \\
\text { Response }\end{array}$ & \\
\hline \multirow{4}{*}{$\begin{array}{c}\text { Treatment } \\
\text { type }\end{array}$} & \multirow{2}{*}{$\begin{array}{l}\text { Imatinib } \\
\text { then } \\
\text { nilotinib }\end{array}$} & $\mathrm{n}$ & 6 & 9 & 2 & 8 & 25 \\
\hline & & $\%$ & $24.0 \%$ & $36.0 \%$ & $8.0 \%$ & $32.0 \%$ & $100.0 \%$ \\
\hline & \multirow{2}{*}{ Imatinib } & $n$ & 23 & 15 & 13 & 10 & 61 \\
\hline & & $\%$ & $37.7 \%$ & $14.5 \%$ & $21.4 \%$ & $16.4 \%$ & $100.0 \%$ \\
\hline \multirow{2}{*}{\multicolumn{2}{|c|}{ Total }} & $\mathrm{n}$ & 29 & 24 & 15 & 18 & 86 \\
\hline & & $\%$ & $33.7 \%$ & $27.9 \%$ & $17.4 \%$ & $20.9 \%$ & $100.0 \%$ \\
\hline
\end{tabular}

Among the eighteen patients who didn't achieve molecular response after 12 months of therapy, ACAS was found in 10 of them (table 4).

\section{Table (4): shows the ACAS during treatment}

\begin{tabular}{|c|l|}
\hline $\begin{array}{c}\text { No of } \\
\text { patients }\end{array}$ & \multicolumn{1}{|c|}{ Type of abnormal chromosome } \\
\hline 2 & negative iso and positive douple ph \\
\hline 1 & amplification 17q22 10\% \\
\hline 1 & del 17p13 14\% and coventional 46xy der (7) \\
\hline 1 & amplification 17q22 13\% \\
\hline 1 & variant ph translocation involving 2,9,22 \\
\hline 1 & $\mathrm{t}(9 ; 22) \mathrm{t}(8 ; 1)$ \\
\hline 2 & del 17p13 18\% \\
\hline 1 & abnormal ph clone der 22 fish $72 \%$ \\
\hline
\end{tabular}


The base line patient characteristics among those harboring ACAS in $2^{\text {nd }}$ bone marrow karyotyping and those who don't are illustrated in table 5.

There was insignificant difference between the two groups.

Table (5): Characteristics of patients according ACAS in $2^{\text {nd }}$ bone marrow karyotyping

\begin{tabular}{|c|c|c|c|}
\hline & $\mathrm{ACAS}+\mathrm{ve}$ & ACAS -ve & p.value \\
\hline Age (Mean, SD) & $31.75 \pm 6.413$ & $30.75 \pm 7.815$ & 0.780 \\
\hline Sex, male/female & $5 / 5$ & $5 / 3$ & 0.532 \\
\hline \multicolumn{4}{|l|}{ Sokal score, } \\
\hline Low & 6 & 4 & \multirow[t]{3}{*}{0.18} \\
\hline Intermediate & 2 & 2 & \\
\hline High & 2 & 2 & \\
\hline \multicolumn{4}{|l|}{ Hasford score } \\
\hline Low & 8 & $\overline{6}$ & \multirow[t]{3}{*}{0.513} \\
\hline Intermediate & 1 & 1 & \\
\hline High & 1 & 1 & \\
\hline \multicolumn{4}{|l|}{ EUTOS score, } \\
\hline Low & 10 & 8 & \multirow[t]{2}{*}{0.843} \\
\hline High & $\mathbf{0}$ & $\mathbf{0}$ & \\
\hline
\end{tabular}

FISH for chromosome 17 abnormality was done on 14 cases who had ACAS in $1^{\text {st }}$ and $2^{\text {nd }}$ bone marrow karyotyping. Five patients $(35.7 \%)$ had positive chromosome 17 abnormality.

All patients with ACAS at presentation achieved hematologic response and 4 $(57.1 \%)$ of them achieved molecular response, $3(42.9 \%)$ of them didn't achieve any 
molecular response. There wasn't significant difference between patients with ACAS and those without regarding achievement of complete hematological and major molecular response (tables 6\&7).

Table (6): ACAS at presentation and hematologic Response

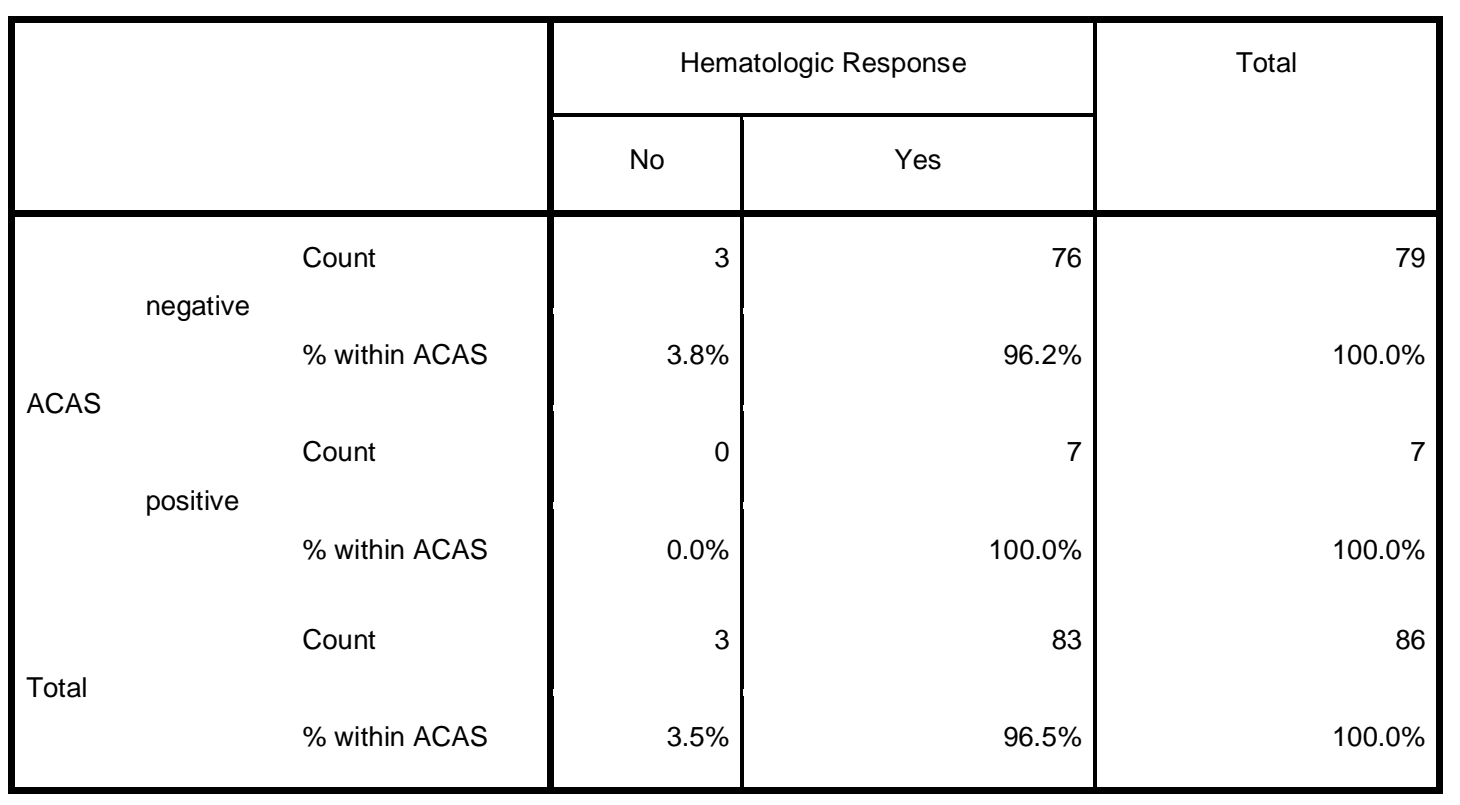

$P=0.456$

Table (7):ACAS at presentation and Molecular Response

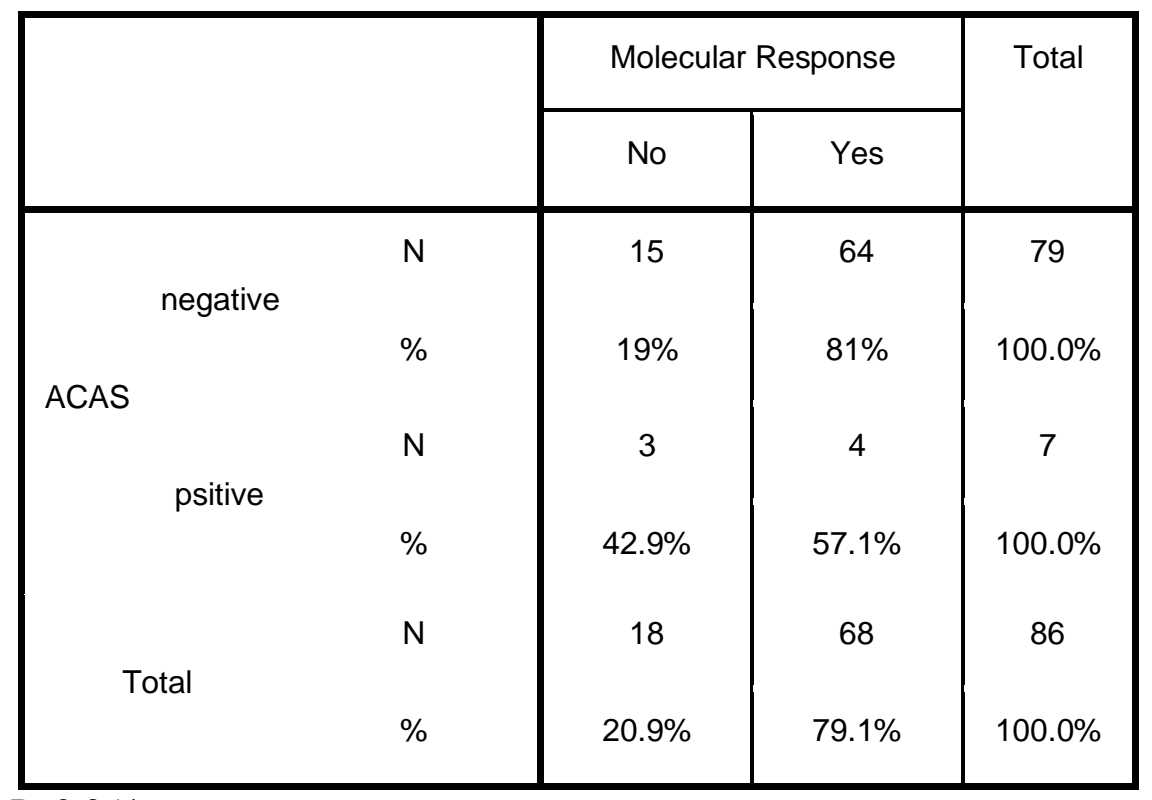

$\mathrm{P}=0.354$ 
Eighty percent of patients who developed ACAS in $2^{\text {nd }}$ bone marrow karyotyping achieved complete hematologic response and 50\% achieved molecular response, there was no statistical significant correlation between presence of ACAS in $2^{\text {nd }}$ bone marrow karyotyping and molecular response achievement (tables 8\&9).

Table (8): ACAS during treatment and Hematologic Response

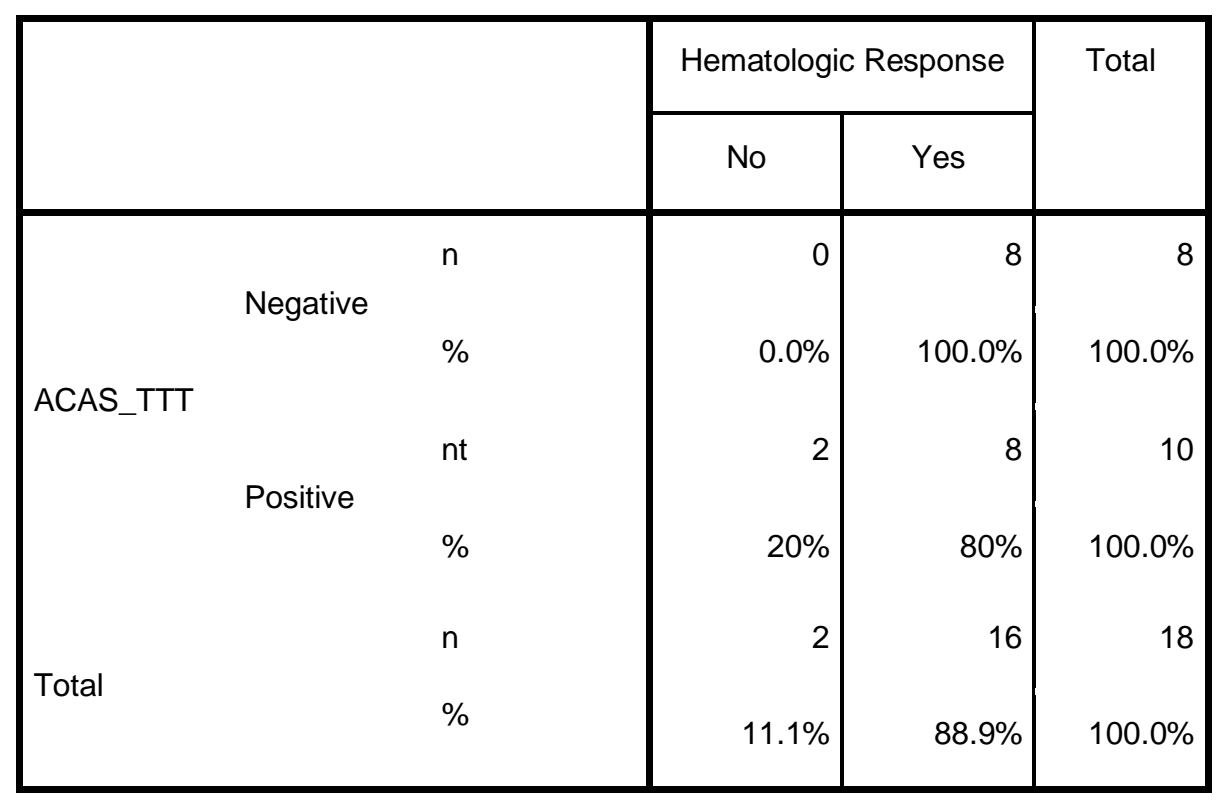

$P=1$

Table (9): ACAS during treatment and Molecular Response

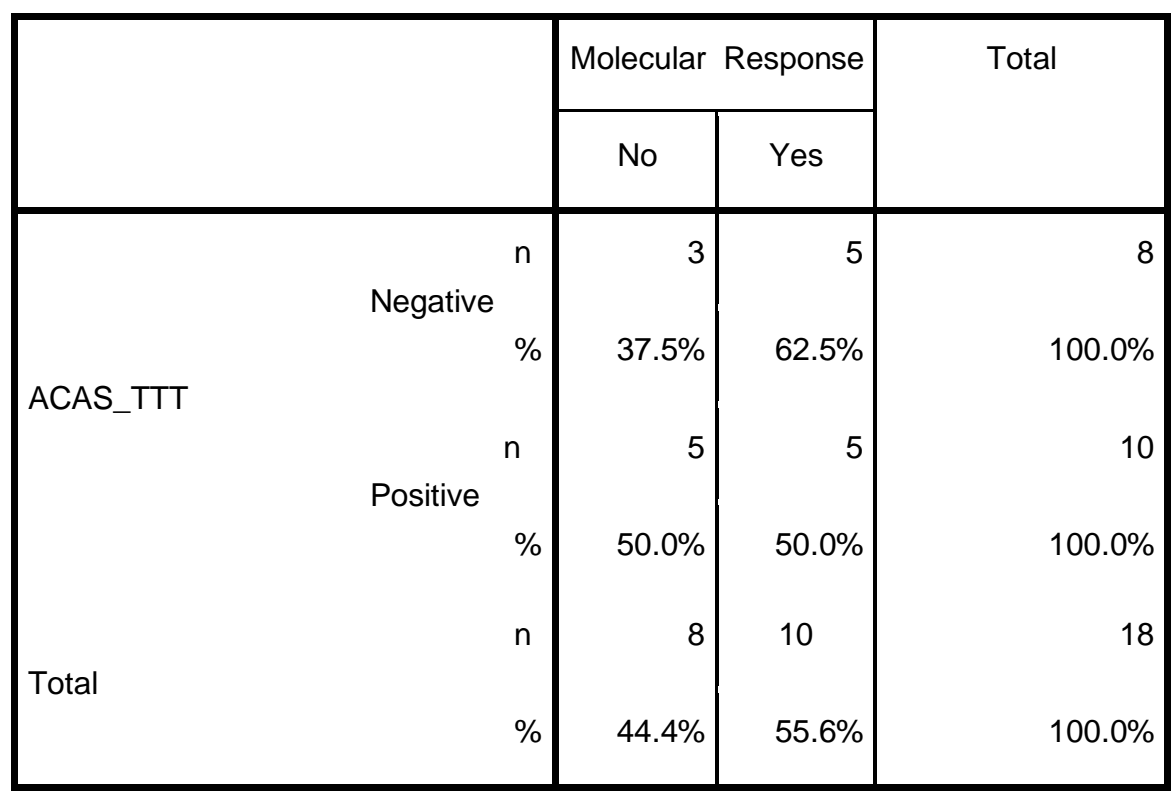

$\mathrm{P}=1$ 
Three of the patients with ch17 abnormalities patients didn't respond to imatinib and were shifted to nilotinib and 2 patient were maintained on imatinib, $60 \%$ (3) achieved molecular response, 40\% (2) didn't achieve molecular response there was no statistical significant correlation between ch17abnormalities and molecular response (tables 10\&11).

Table (10): Treatment and ch17abnormalities

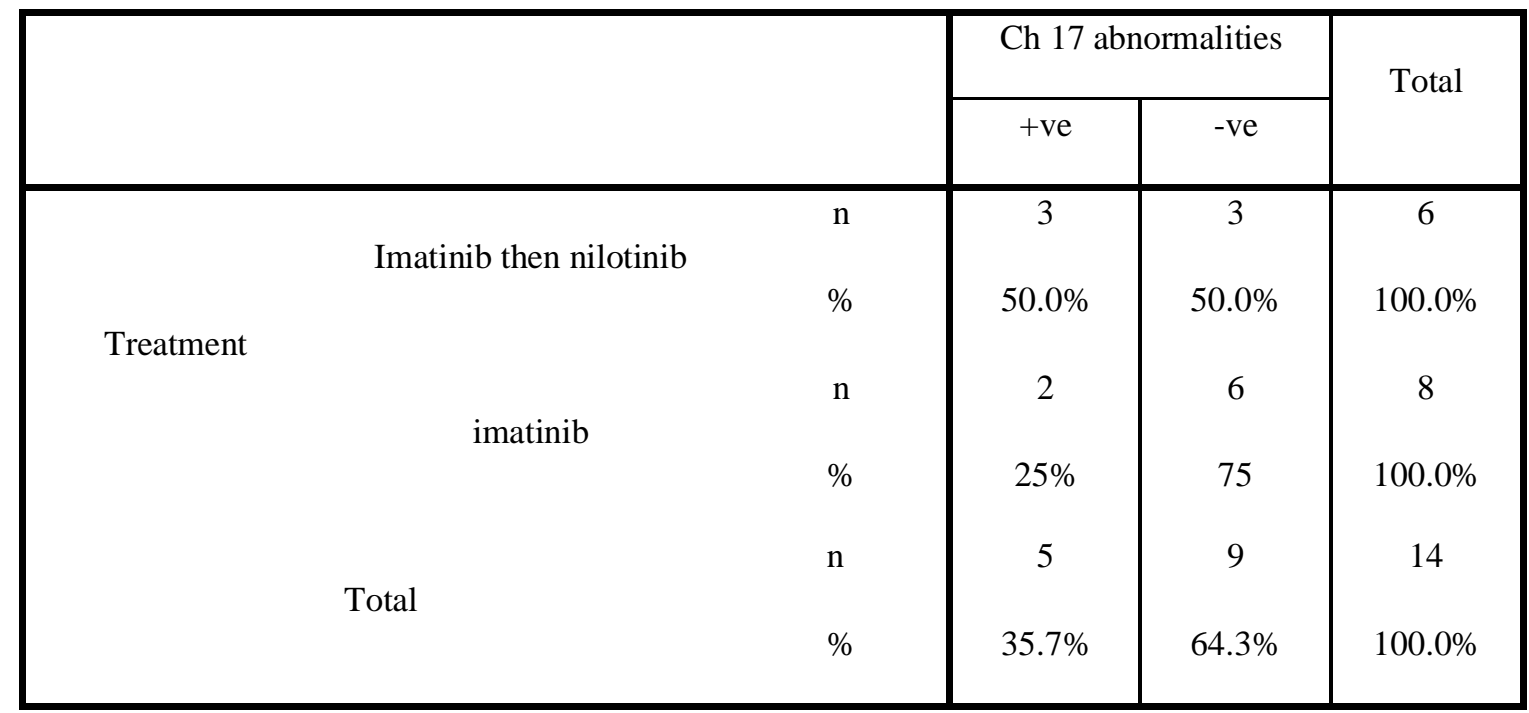

$P=1.0$

Table (11): ch 17 abnormalities and Molecular Response

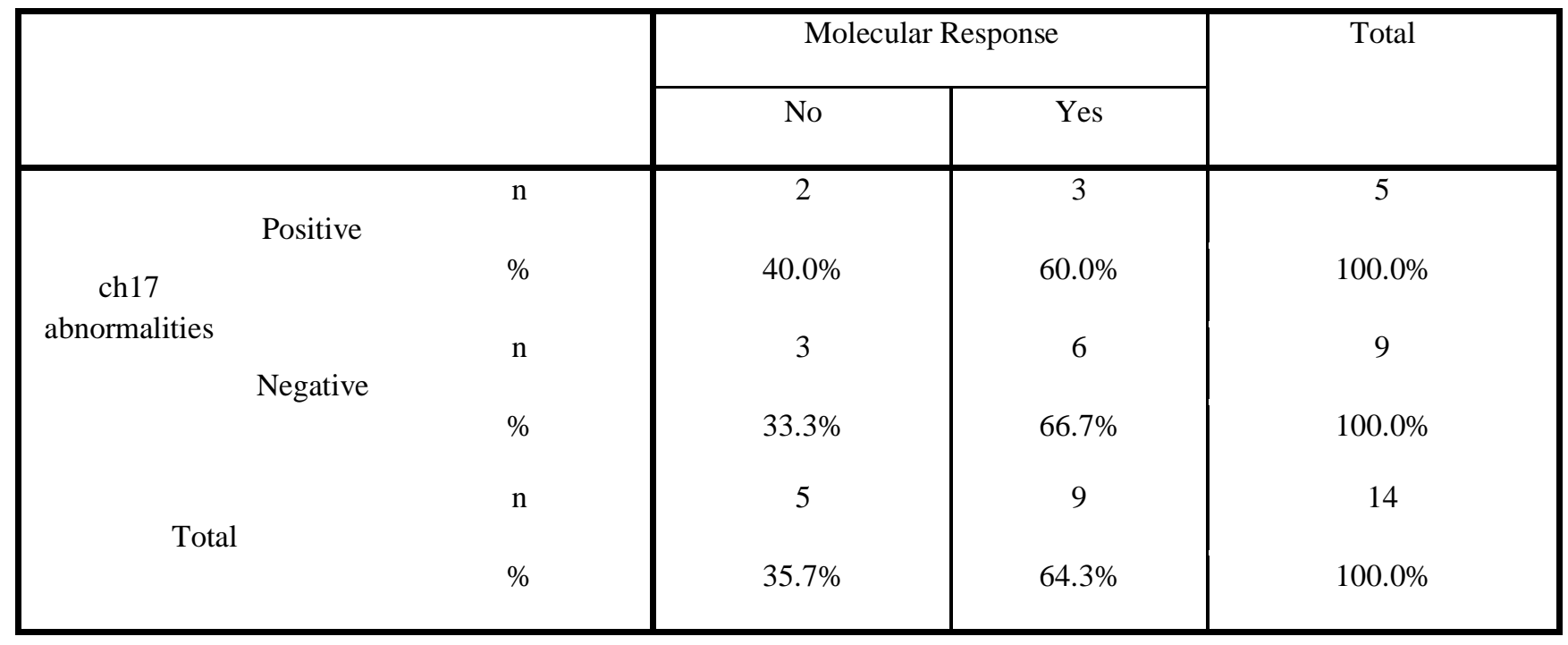

$P=1.0$ 
About two thirds (65.7\%) of patients had shown molecular response at $\leq 1$ year which didn't differ in ACAS positive than in ACAS negative groups at presentation (Fig3\&4).

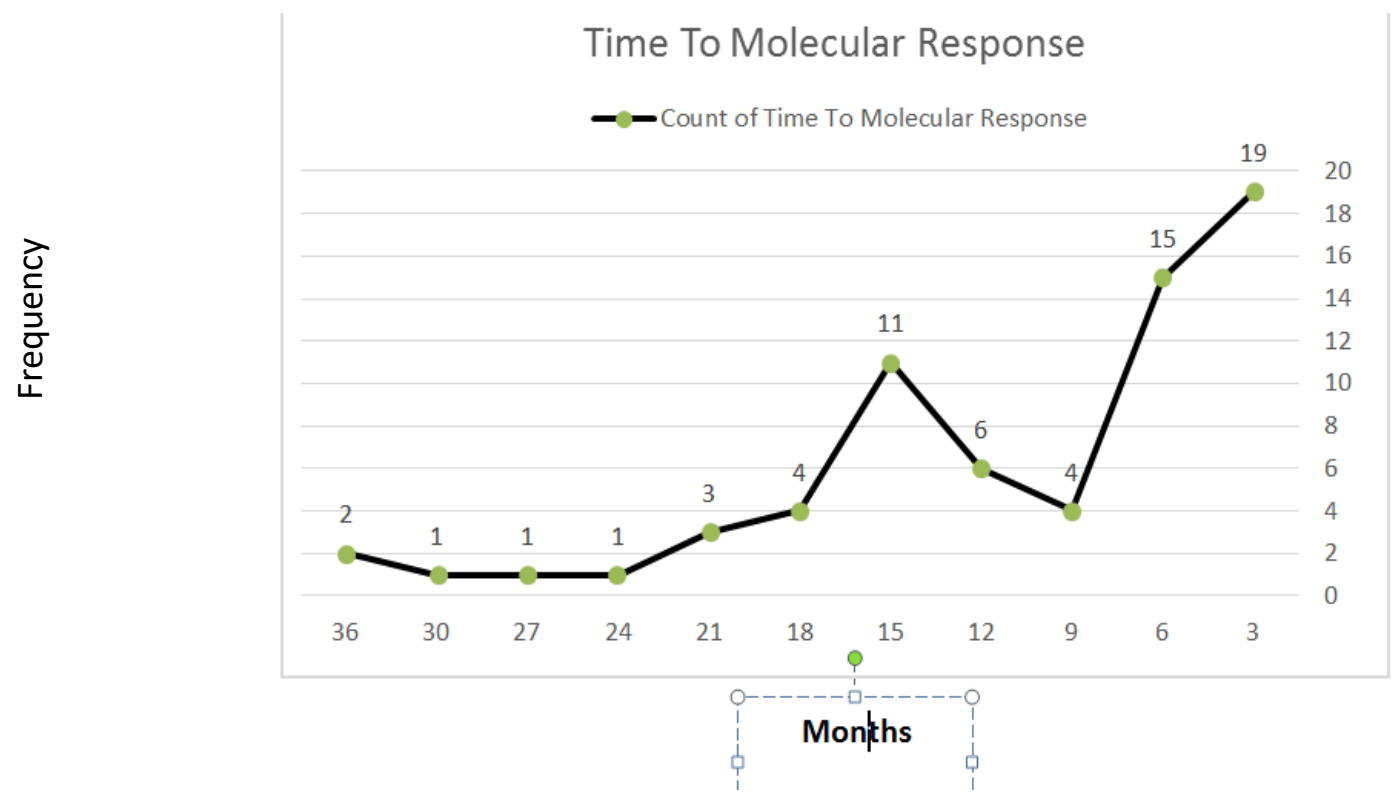

Figure (3): Time to molecular response for all patients

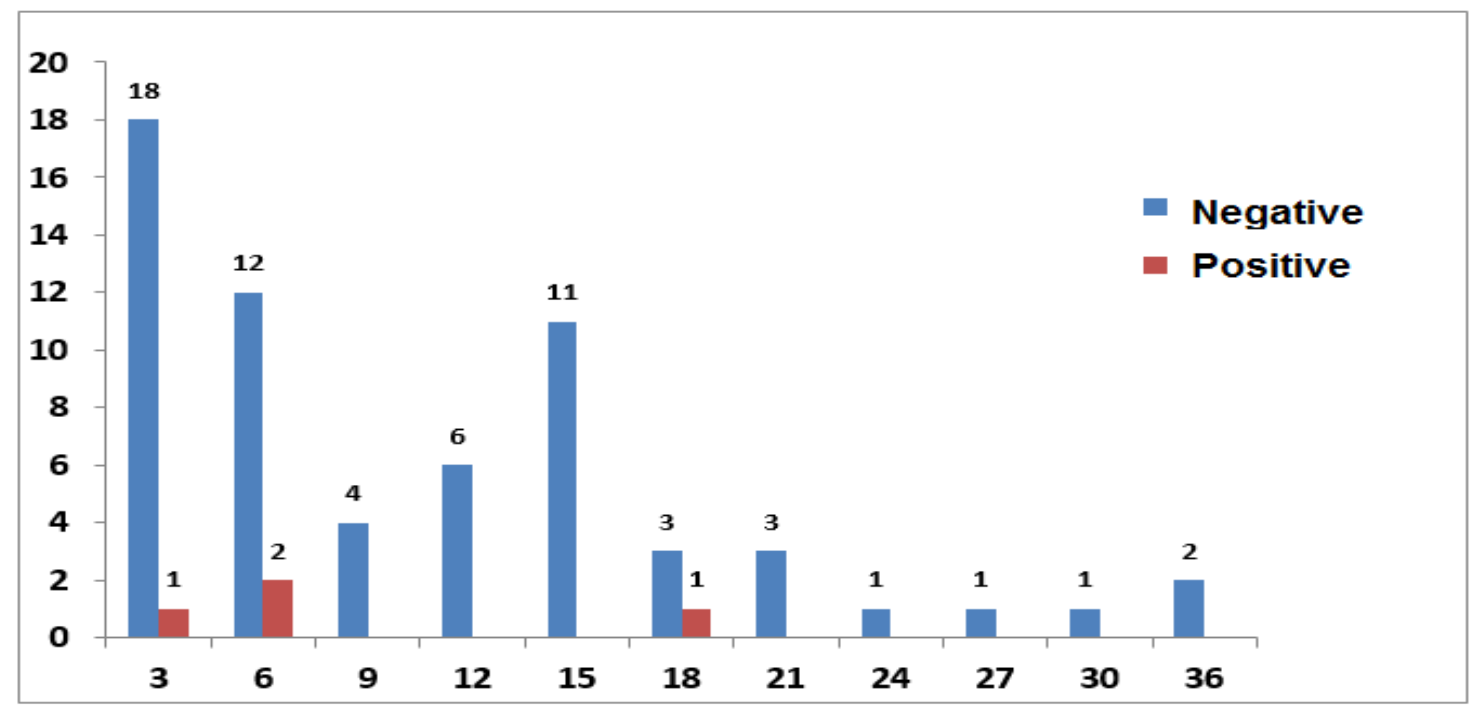

Figure (4): Time to molecular response in patients with ACAS positive and negative at presentation 
In ACAS +ve group at diagnosis, the 5 years cumulative survival was $50 \%$ (mean survival 3.91 years) and in patients without additional anomalies, the 5 years cumulative survival was $60 \%$ (mean survival 4.93 years).There was no statistical significant difference between the two groups $(p=0.692)$ (Fig5).

Patients developed ACAS during treatments 5 years cumulative survival was 50 $\%$, mean survival for ACAS positive and negative groups 5.29,3.14 years respectively $\mathrm{p}$ value $=0.221$ (Fig6).

Patients developed ch 17 abnormalities during treatments 5 years cumulative survival was $38 \%$, mean survival for them was 3.7 years p value $=0.9$ (Fig7).

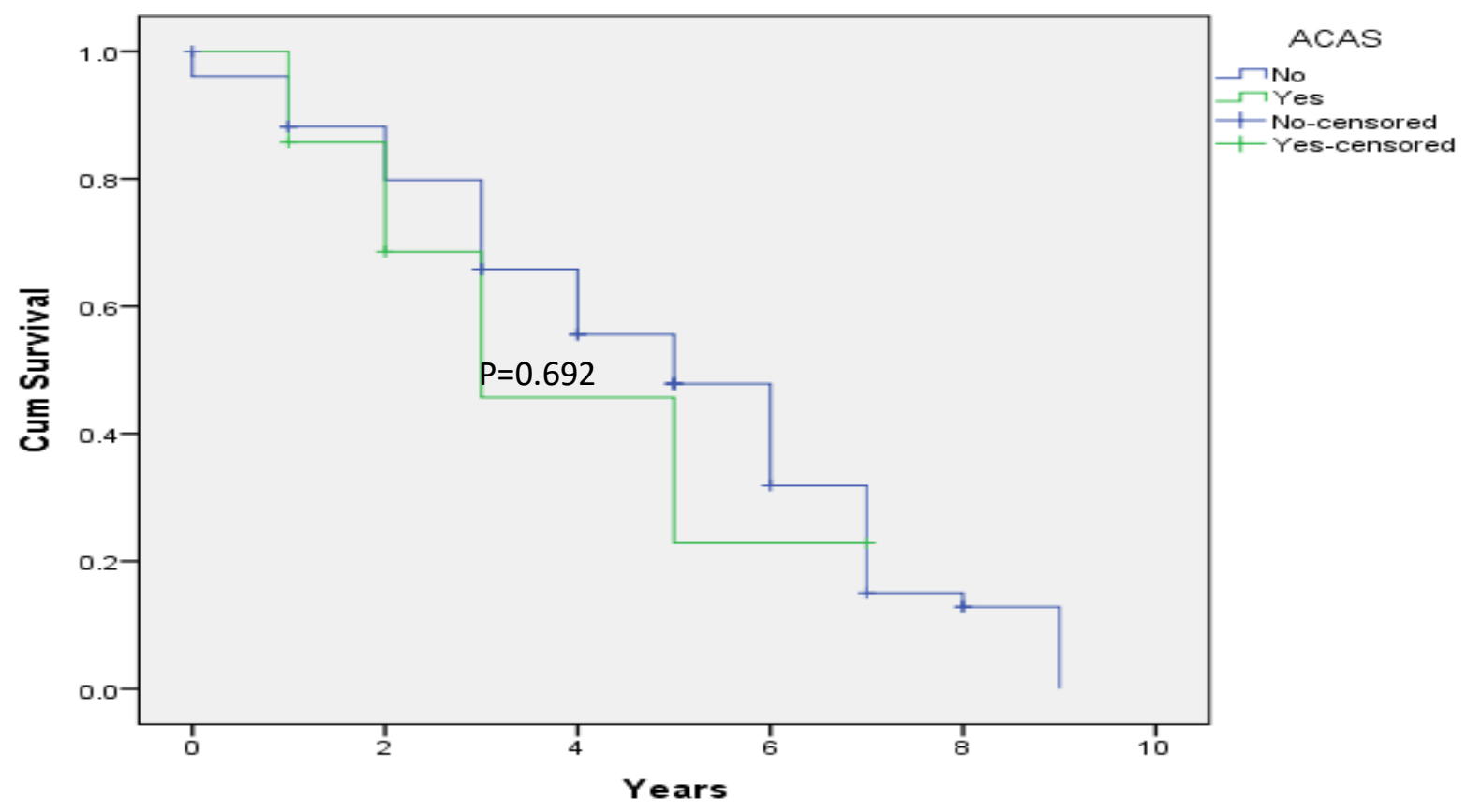

Figure (5): Kaplan meir curve for ACAS at diagnosis 


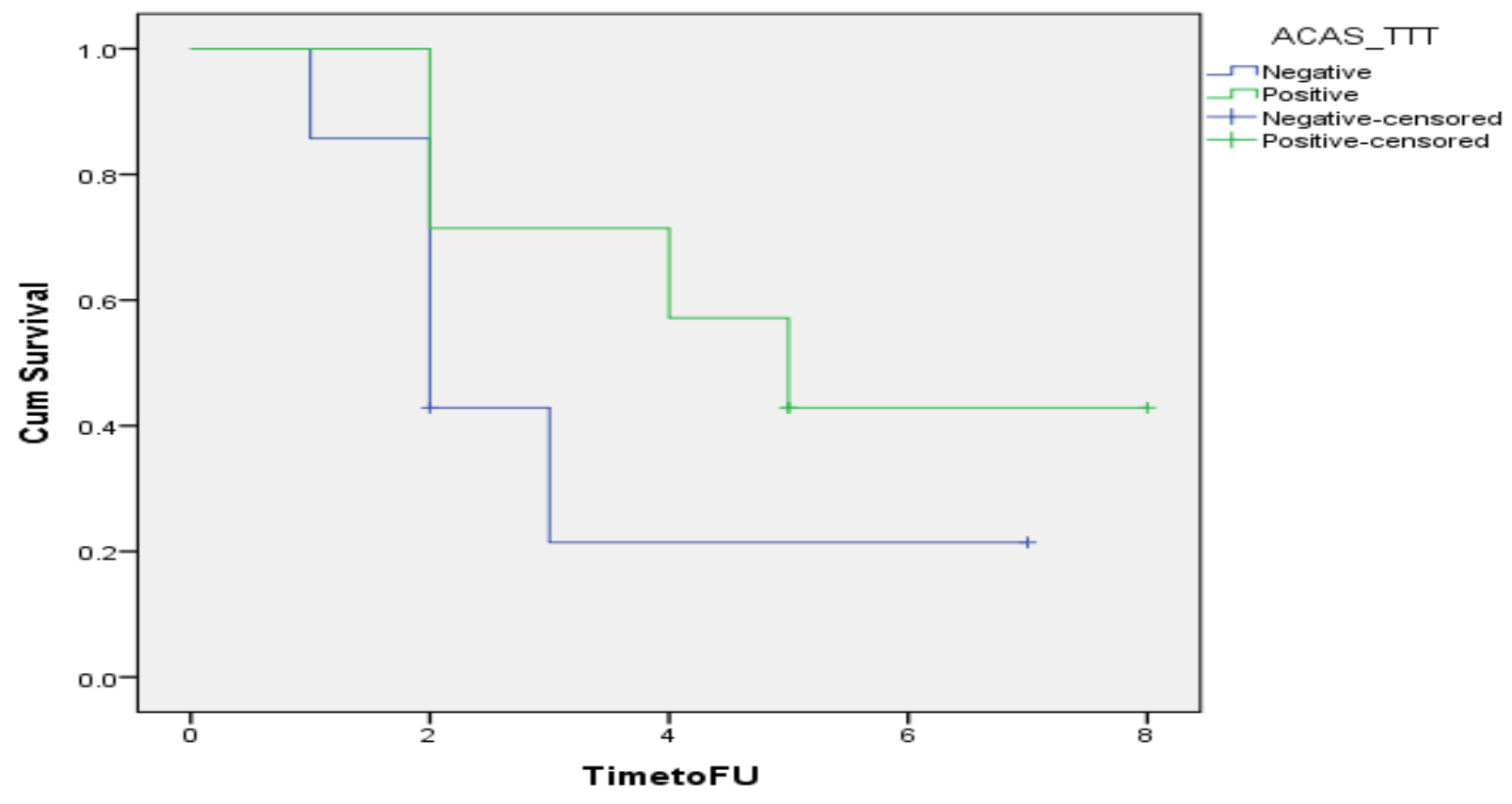

$P=0.221$

Figure (6): Kaplan Meir curve for ACAS during treatment

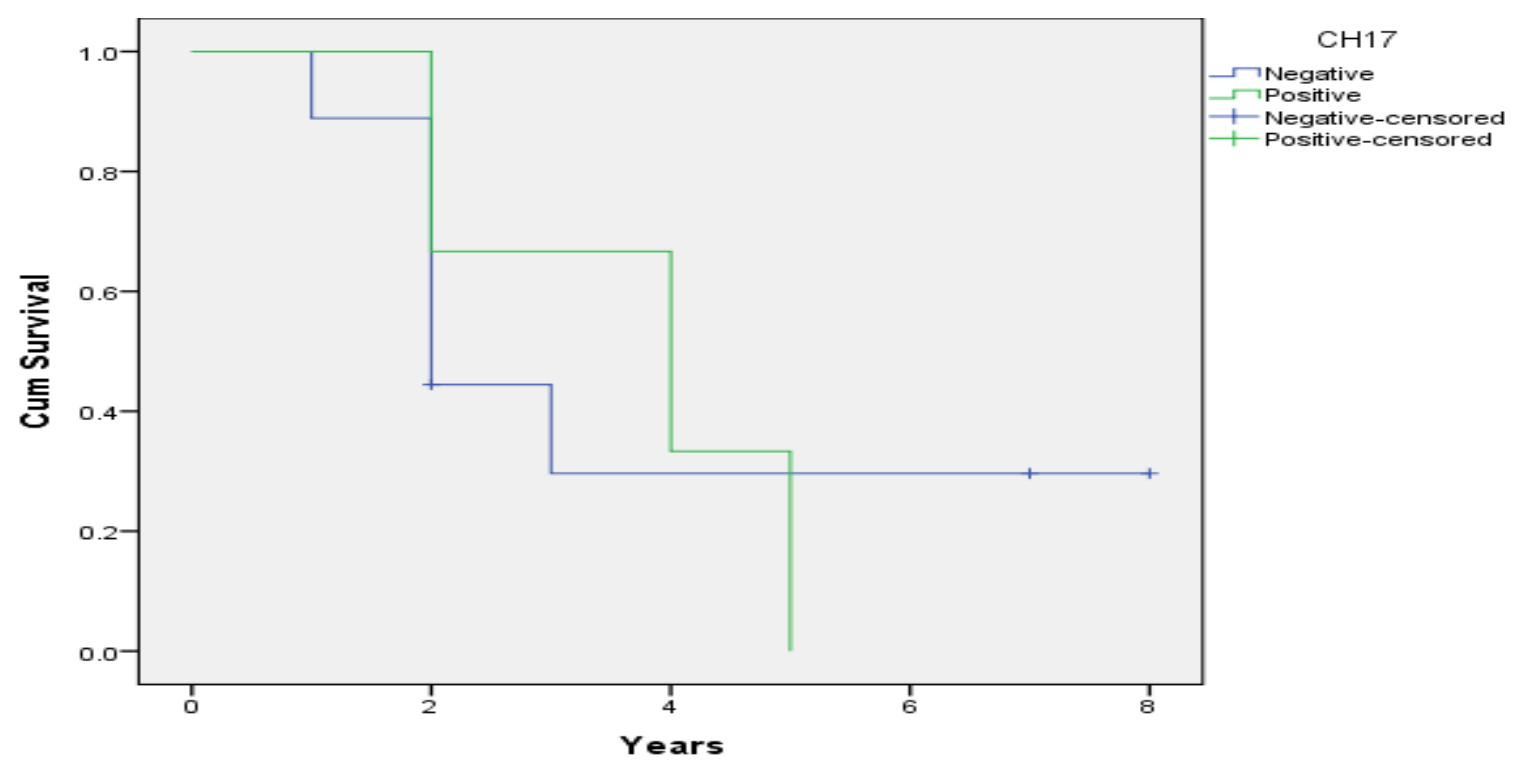

Figure (7): Kaplan Meir curve for ch 17 during treatment 


\section{Discussion}

Recently median age of CML has fallen in the fourth decade. Reasons for this early incidence of CML are not fully known (Babu et al., 2015).

In our study, ACAS was found in $7(8.1 \%)$ at time of diagnosis. Hsiao and his colleague showed that $69(82.1 \%)$ of patients presented with the classic $\mathrm{Ph}$. chromosome, $6(7.2 \%)$ with a variant $\mathrm{Ph}$ chromosome, and 9 (10.7\%) with additional chromosome abnormalities (Hsiao et al., 2011). Clonal ACAS occurred in 21/378 evaluable patients (5.6\%) in another study (Luatti et al., 2012). ACAS was found in $2 \%$ in the study of Castagnetti and his colleague (Castagnetti et al., 2015). Also Madhave and his colleague found that ACAS was present in 92 of 1,367 patients (6.7\%) at the time of diagnosis or progression (Madhav, 2016), which is consistent with our study.

In our study, ACAS was common in females and this was in disagreement with Luatti et al., study in which ACAS was increased in males (Luatti et al., 2012). This can be attributed to the un equal sex distribution among patients in our study.

In our study, all patients with ACAS (7 patients) presented in chronic phase, 6 of them had low eutos score with minor route anomalies. In Crisan et al., study, 9 patients were in chronic phase and 2 patients were in accelerated phase and low eutos score was found in 8 patients with minor route and 3 patients with major route (Crisan et al., 2015). In another study, patients with ACAS belonged to high soakal, intermediate hassford and low eutos scores (Luatti et al., 2012).

In our study no cases were found to have loss of Y chromosome while Luatti and his colleague observed that the most frequent abnormality was the loss of Y chromosome (43\%). This high frequency of The $-\mathrm{Y}$ in the other study can be explained by increasing age of patients (Luatti et al., 2012). 
In our study Variant $\mathrm{Ph}$ was present in $3(3.5 \%)$ patients whereas in Luatti et al., study, one patient had variant $\mathrm{Ph}$ chromosome (Luatti et al., 2012) and Variant $\mathrm{Ph}$ chromosome was seen in 9 patients $(0.6 \%)$ in Medhave study which was not considered an ACAS (Madhav, 2016).

More specifically about hematological response, we achieved $84.9 \%$ recovery at the end of three months of treatment. Singh et al., reported a similar hematological response (>90\%) (Singh et al., 2017). Also Gugliotta et al., found that CHR at 3 months were $97 \%$ and $96 \%$ in older and younger patients, respectively (Gugliotta et al., 2011).

Fifty seven patients with ACAS at presentation achieved MMR while Luatti and his collegue found that $67 \%$ of patients with ACAS achieved MMR (Luatti et al., 2012).

In our study ACAS during TKI treatment was found in $10(55.6 \%)$ patients mean age for patients with ACAS during treatment was (31.75 +5.676). All patients presented as low eutos score of which 5 had minor route and 5 had major route and all were in chronic phase while Crisan and his colleague reported that ACAS during treatment was found in 17 (8.54\%) patients, median age was 49.7 ranged (25-71), 94.1\% of patients presented as low eutos score and $5.9 \%$ of them presented as high eutos score. ACAS were distributed as 8 minor route and 9 major route and all were in chronic phase (Crisan et al., 2015).

Eighty percent of patients who developed ACAS during treatment achieved CHR and 50\% achieved MMR while Alhuraiji and his colleague reported that $93 \%$ achieved CHR and $73 \%$ achieved MMR (Alhuraiji et al., 2017).

In our study ch 17 abnormalities were found in 5 patients during treatment by Imatinib ( 1 of them achieved molecular response the other patients were shifted to tasigna , 3 of them achieved molecular response).In 
Wang et al., study i(17) (q10) was found in 2 patients before treatment . They neither achieved cytogenetic nor molecular response and it was found in 13 patients during treatment ( 2 of them achieved cytogenetic response and 1 achieved major molecular response) (Wang et al., 2016).

Williams reported that patients with ACAs at diagnosis had better treatment responses than whose ACAs appeared during the course of treatment (Williams, 2016).

Poor patient adherence to the CML treatment therapy might be the predominant reason for the inability to obtain adequate hematological and molecular responses in our study. Maintaining good adherence to treatment is considered an important therapeutic target (Yamamoto et al., 2014).

In our study, non compliance was found in 13 (17.8\%) patients whereas in the study of Babu and his colleague, non-compliance was 6\% (babu et al., 2015). This difference was due to the low socioeconomic state and lack of insurance.

Three patients in our study gained parenthood during the study period (one male patient and two female patients)\&had to discontinue treatment before pregnancy and received interferon instead of TKI.

In our sudy,in the ACAS+ve group at diagnosis, the 5 years cumulative survival was $50 \%$ (mean survival 3.91 years) and in patients without ACAS the 5 years cumulative survival was $60 \%$ (mean survival 4.93 years). In Alhuraiji et al., study, overall survival was $93 \%$ and patients with ACAS overall survival was $83 \%$ (Alhuraiji etal.,2018).

Patients who developed ACAS during treatments had a 5 years cumulative survival $50 \%$ whereas Issa and his colleague found overall survival 79\% (Issa etal., 2017).Also, Wiliams reported comparable survival of patients with ACAS at presentation and during treatment to our study (Williams, 2016). 
In our study, patient with ch 17 abnormalities had 5 years cumulative survival $38 \%$ which was more or less similar to that reported by Wang et al., (30\%) (Wang et al., 2016).

The poor prognosis of patients with ch 17 abnormalities is likely related to p53 deletion; p53 is a tumor suppressor and plays a critical role in regulating cell-cycle arrest and apoptosis. The inactivation of p53 causes genomic instability, neoplastic transformation, and disease progression (Wang et al., 2016).

We concluded that ACAS at diagnosis and during treatment has no impact on CML poor risk parameters (WBC count,hasford score, sokal score) which denotes that other factors are more significant. Time to molecular response didn't differ between ACAS +ve \&-ve patients at diagnosis this can be attributed to bad compliance \&most patients were in chronic phase. Presence of ACAS at diagnosis and during treatment and ch 17 abnormalities had no impact on HR or MR achievement as there was few number of patients harboring it. Survival didn't differ between patients with ACAS +ve \&-ve groups at diagnosis, during treatment because most were minor route. Here we agree with that minor route at diagnosis shouldn't be considered as worrying to failure of response. Survival didn't differ between patients with and without ch 17 abnormalities because of non universal treatment and few number of patients.

We recommend to do Further larger prospective studies with better adherence to treatment to confirm our results. We recommend also studying impact of ACAS presence on possibility of discontinuation of drug. Also studying the mechanism of resistance associated with ACAS to TKI treatment is important. 


\section{References:}

Alhuraiji A, Kantarjian H, Boddu P, etal. (2018): Prognostic significance of additional chromosomal abnormalities at the time of diagnosis in patients with chronic myeloid leukemia treated with frontline tyrosine kinase inhibitors. Am J Hematol; 93:84-90.

Azzazi MO and Mattar MM(2013):Arab Leukemia Net (ALN) registry and data base for chronic myeloid leukemia (CML) in North Africa \& Middle East (AFME) region. A call for action and declaration of intent. Eln newsletter- special edition abstracts. NEW FRONTIERS OF MYELOID NEOPLASIAS ELN Frontiers Meeting 2013.

Babu GK, Thanky A, Jacob LA, et al. (2015): Outcome of young adults with chronic myeloid leukemia treated with upfront imatinib: A single institutional experience. J Appl Hematol; 6:157-61.

Crisan AM, Coriu D, Arion C, et al. (2015): The impact of additional cytogenetic abnormalities at diagnosis and during therapy with tyrosine kinase inhibitors in Chronic Myeloid Leukaemia.Journal of Medicine and Life ;8(4) : 502-508

Castagnetti F, Gugliotta G, Baccarani M, et al. (2015): Differences among young adults, adults and elderly chronic myeloid leukemia patients. Annals of Oncology 26: 185-192.

Gugliotta G, Castagnetti F, Palandri F, et al. (2011): Frontline imatinib treatment of chronic myeloid leukemia: no impact of age on outcome, a survey by the GIMEMA CML Working Party. Blood; 117(21): 5591-5599)

Hsiao HH, Liu YC, Hui-Jen Tsai HJ, et al., Additional chromosome abnormalities in chronic myeloid leukemia Kaohsiung Journal of Medical Sciences ;27; 49-54.

Issa GC, Kantarjian H, Gonzalez GN, et al. (2017): Clonal chromosomal abnormalities appearing in Philadelphia negative metaphases during CML treatment. Blood; 7:143.

Luatti G, Castagnetti F, Marzocchi G etalL.,(2012): Additional chromosomal abnormalities in Philadelphia-positive clone: adverse prognostic influence on frontline imatinib therapy: a GIMEMAWorking Party on CML analysis. BLOOD; 120(4) :761-768

Madhav D. (2016): Additional chromosomal abnormalities in chronic myeloid leukemia: Lest we forget. Annals of Oncology; 27(9) 
Sakurai M, Mori T, Karigane D, et al. (2015): Unfavorable outcome of chronic myelogenous leukemia in adolescent and young adults treated with tyrosine kinase inhibitors. Int J Hematol ; 102:342-348.

Wang W, Cortes J E, Pei Lin P, et al. (2015): Clinical and prognostic significance of 3q26.2 and other chromosome 3 abnormalities in chronic myelogenous leukemia in era of tyrosine kinase inhibitors. blood

Wang W, Cortes JE, Tang G, et al. (2016): Risk stratification of chromosomal abnormalities in chronic myelogenous leukemia in the era of tyrosine kinase inhibitor therapy. BLOOD; 127(22): 2742-2752

Williams L.(2016): Additional chromosomal abnormalities prognostic for CML. Licensed from medwire News with permission from Springer Healthcare Ltd. OSpringer Healthcare Ltd

Yamamoto E, Fujisawa S, Hagihara M, et al. (2014): European Treatment and Outcome Study score does not predict imatinib treatment response and outcome in chronic myeloid leukemia patients. Cancer; 105 (1):| 105-109. 